\title{
Making consequentialism more appealing
}

Several papers in this issue of the Journal of Medical Ethics focus on dilemmas of various sorts. Our feature article and accompanying commentaries discuss the dilemma facing Japanese citizens in implementing tsunami-tendenko, a highly effective, lifesaving strategy for responding to tsunamis which nevertheless requires people to act contrary to certain powerful moral intuitions. Two papers-one by Bram Wispelwey and one by Robert Torrance-reflect on what considerations should prevail in deciding how to proceed when the requirement to ensure treatments are safe and effective conflicts against patient autonomy. And Charles Foster speculates about how the law is likely to weigh people's freedom to disclose genetic information about themselves against the privacy of others to whom the information also applies.

\section{CONFLICT BETWEEN CONSEQUENTIALIST AND DEONTOLOGICAL INTUITIONS: A REAL-LIFE CASE STUDY}

Philosophers are fond of constructing elaborate thought experiments to test our moral intuitions. 'Trolley problems', an increasingly elaborate mainstay of moral philosophy since Philippa Foot first described them in the 1960s, are designed to weigh consequentialist moral intuitions against conflicting deontological ones. Trolley problems have attracted the attention of psychologistsnotably Joshua Greene and colleagues ${ }^{1}$ wishing to gauge the interaction between, and influence of, reason and emotion on moral judgment. Some argue that moral judgment is made on the basis of emotion alone, with reason providing merely post-hoc rationalisations of decisions already made. ${ }^{2}$ Emotion, these researchers hold, leads us to make deontological moral judgments, whilst reason leads us to make consequentialist ones. This claim gains support from more recent research that finds a correlation between a tendency towards consequentialist moral judgments and antisocial personality traits, including psychopathy. ${ }^{3}$ Psychopathy, of course, is characterised by stunted emotional response.

The conflict between consequentialist and deontological moral intuitions that is highlighted by hypothetical trolley problems also arises in a far more pressing, real-life context that is the focus of this issue's feature article. When a tsumani strikes, should we try to help others before we try to save ourselves, or should we run for the hills? Satoshi Kodama discusses the controversial strategy of tsunami-tendenko, which the Japanese government has been promoting in schools since the earthquake and tsunami of 2011 claimed many thousands of lives (see page 361, Editor's choice). Tsunami-tendenko involves teaching children that, in the event of a tsunami, they should focus only on themselves by evacuating immediately to a safe area. They should not delay by trying to save or wait for others, even their loved ones. Striking data from the 2011 tsunami shows that tsunami-tendenko is vastly more effective at maximising survival than strategies in which people delay evacuating in order to save others or to evaculate collectively. A consequentialist analysis, then, strongly supports tsunami-tendenko. However, Kodama identifies some deontological considerations that appear to conflict with tsunami-tendenko. First, by teaching schoolchildren not to help their loved ones, the strategy might be seen as promoting an unappealing brand of egoism. Second, the strategy is unrealistic: psychologically, people are likely to find it very difficult to resist helping their loved ones. Kodama argues that neither of these deontological considerations need be persuasive. One's motivation for practising tsunami-tendenko need not be egoistic (one can, instead, be motivated by a desire to act collectively with others in order to maximise the number of lives saved). And the psychological obstacles to implementing it can be reduced by cultivating trust among loved ones that everyone will save themselves: if people are confident that their friends and relatives are already making their way to safety, they will find it easier to resist waiting for them.

\section{UNSELFISH SELF-PRESERVATION}

Both commentaries on this article are supportive of Kodama's view that tsunamitendenko should be implemented. Justin Oakley argues that tsunami-tendenko can be defended from a virtue ethics perspective, and also offers reflections that bolster Kodama's argument that the strategy is not objectionably egoistic (see page 364). Atsushi Asai, whilst agreeing that it would be a good thing if everyone practised tsunami-tendenko, is rather more pessimistic than Kodama about whether it would be possible to surmount the psychological obstacles to its successful implementation (see page 365 ).

It is unusual for us to publish a feature article in which all the commentators are in full agreement with the core argument of the article's author. In this case, it seems a no-brainer: of course Japan should implement tsunami-tendenko, given that it is vastly superior to other evacuation strategies as a means to maximise survival. The problem is how to get Japanese citizens to buy into it without requiring them to be consequentialist psychopaths of the sort discussed by Bartels and Pizarro. ${ }^{3}$

One relevant consideration that is not mentioned in the discussion, but which could affect people's willingness to practise tsunami-tendenko, is the likely influence of framing effects in shaping people's decisions about how to act when disaster strikes. A framing effect is a cognitive bias in which people's response to information is influenced by the way in which that information is presented. In the 1980s, Amos Tversky and Daniel Kahneman famously demonstrated that, in a hypothetical scenario, people's preferences about treatment options for a deadly disease were shaped by the way in which the treatments were described; specifically, by whether the treatments were described in terms of how many lives they would save or in terms of how many deaths would result from them. Framing the treatments in terms of lives saved made participants far more likely to choose them over competing options. ${ }^{4}$

Kodama frames tsunami-tendenko in a way that emphasises self-preservation over helping others. He characterises it as, 'run for your life to the top of the hill and never mind others or even your family when the tsunami comes'. This way of presenting the strategy makes salient that tsunami-tendenko involves prioritising one's own interests over those of others. As such, it is easy to see why some see it as unacceptably, and unrealistically, selfish. However, it could alternatively be characterised as, 'run for your life to the top of the hill to ensure that others are not tempted to endanger themselves by waiting for you'. This more positive 
presentation makes salient that practising tsunami-tendenko can be motivated by a desire to promote the survival of others as well as oneself, and that taking care of oneself can be a way of fulfilling one's duties to others. Given this, it emphasises ways in which tsunami-tendenko can promote both the consequentialist aim of maximising lives saved and the deontological considerations-such as our strong desire to look after our loved ones-that threaten to thwart the successful implementation of the strategy. Data on framing effects suggests that the latter, positive, presentation of tsunami-tendenko could play a significant role in making it more appealing, and consequently in improving the success of its implementation.

\section{THE ETHICS OF HIV TRANSMISSION}

Elsewhere in this issue, two papers explore different sets of ethical issues relating to HIV. Bram Wispelwey notes that there are moves in the United States to relax the current ban on organ donations from HIV-positive patients (see page 367). Soon, donations from such patients may be permitted in cases where the recipient is also HIV-positive. Wispelwey notes that this raises the issue of whether HIV-negative patients should also be allowed to receive organs from HIV-positive donors. He argues that, given the risks surrounding organ donation (and those surrounding not receiving an organ that one needs), a universal ban on HIV-positive to HIV-negative organ donation is likely unjustifiable.

Catherine Stanton considers legal and ethical issues surrounding the transmission of HIV from women to their babies (see page 375). She reflects on whether laws used to prosecute those who transmit HIV to sexual partners could be used to prosecute mother-to-baby transmission through pregnancy, childbirth, or breastfeeding. She is doubtful that such prosecutions would occur, but she argues for the importance of evaluating whether, and in what circumstances, criminalising the transmission of disease is the best way of safeguarding public health.

\section{INFORMATION, CONSENT, AND INFORMED CONSENT}

Robert Torrance continues a debate, started by Charlotte Blease in an earlier issue of the Journal of Medical Ethics, about what conditions must be met in order for patients to consent to receive electroconvulsive therapy (ECT) (see page 371). Blease had argued that patients' attention should be drawn to disagreements about ECT's effectiveness and about the mechanism by which it works. In addition to contesting Blease's portrayal of research on ECT, Torrance debates the relevance of ensuring that patients understand the mechanism by which their proposed treatments are effective.

Charles Foster addresses a very different issue relating to medical information (see page 379). He considers whether we would have legal grounds to object to someone's public disclosure of her medical information in cases where this would effectively also disclose our own medical information. (The example Foster uses involves a set of identical twin celebrities, where the decision of one to publicise his genetic disease would lead the public to infer, correctly, that his twin has the same disease.) In doing so, he weighs the 'joint account' model of medical information-which compares the shared ownership of genetic information to the shared ownership of funds in a joint bank account-against other legal approaches to confidentiality, and speculates about how it is likely to be viewed in court.

\section{ENVIRONMENTALLY FRIENDLY MEDICINE}

Finally, Cristina Richie provides an overview of the emerging field of 'green bioethics', which is concerned with the environmental impact of the medical industry. She focuses on assisted reproductive technologies (ARTs), and argues that green bioethics has reason to be concerned about these technologies because they result in the creation of more resourcedepleting, carbon-emitting humans (see page 383). Richie suggests some ways in which the ART industry could offset the environmental impact of the new humans it helps to create, and argues for their importance.

\section{REFERENCES}

1 Greene JD, Sommerville RB, Nystrom LE, et al. 'An fMRI investigation of emotional engagement in moral judgment', Science 2001;293:2105-08.

2 Haidt J. 'The emotional dog and its rational tail: A social intuitionist approach to moral judgment', Psychological Review 2001;108:814-34.

3 Bartels DM, Pizarro DA 'The mismeasure of morals: Antisocial personality traits predict utilitarian responses to moral dilemmas', Cognition 2011;121:154-61.

4 Tversky A., Kahneman D. 'The framing of decisions and the psychology of choice', Science 1981;211:453-8. 